\title{
PRINCIPIO 10 Y DESARROLLO ELÉCTRICO: PARTICIPACIÓN Y ACCESO A LA JUSTICIA EN MIRAS A LA IMPLEMENTACIÓN DE TRIBUNALES ESPECIALIZADOS*
}

["Principle 10 and Power Development: Participation in Justice and Access to it with a View Towards Implementing Specialized Courts"]

\author{
Pilar Moraga Sariego** \\ Universidad de Chile, Santiago
}

\begin{abstract}
RESUMEN
El principio 10 de la "Declaración de Río" de 1992 construido sobre la base de la participación ciudadana, el acceso a la información y el acceso a la justicia ambiental, adquiere especial relevancia en la prevención de conflictos socio-ambientales y en el logro de un desarrollo sustentable. La judicialización del sector eléctrico chileno da cuenta de esta realidad, en un contexto normativo que evoluciona hacia la instalación de una justicia especializada en materia ambiental.
\end{abstract}

Palabras clave

Principio 10 - "Declaración de Río" - Desarrollo sustentable - Acceso a la justicia - Desarrollo eléctrico.

\begin{abstract}
Principle 10 of the "Rio Declaration" of 1992, based on citizenship participation, access to information and access to environmental justice, gains special importance in social-environmental conflicts prevention and in the achievement of a sustainable development. The judicialization of the Chilean power production accounts for this reality, within a regulatory context evolving towards the installation of a specialized justice in environmental matter.

\section{KEYWORDS}

Principle 10 - "Rio Declaration" Sustainable development - Access to justice - Power production development.
\end{abstract}

RECIBIDO el 23 de octubre y APROBADO el 2 de noviembre de 2012.

${ }^{*}$ El presente trabajo fue realizado gracias al apoyo del programa FondECYT de iniciación $\mathrm{N}^{\circ} 11100288$, titulado: "Instrumentos para la implementación de una política energética sustentable.

** Investigadora del Centro de Derecho Ambiental de la Facultad de Derecho de la Universidad de Chile. Dirección postal: Pío Nono s/n, Providencia, Santiago, Chile. Correo electrónico:pmoraga@derecho.uchile.cl 


\section{INTRODUCCIÓN}

El principio 10 de la "Declaración de Río", fruto de la Conferencia Mundial de Naciones Unidas sobre el Medio Ambiente y el Desarrollo de 1992, define los principios de participación, acceso a la información y acceso a la justicia ambiental, como tres elementos interdependientes de cuya realización depende la implementación del desarrollo sustentable a escala global, nacional y local. Esta idea fue refrendada en el documento final elaborado en la Cumbre de Naciones Unidas sobre el Desarrollo Sustentable, realizada veinte años más tarde en Río de Janeiro, Brasil, el cual se titula: "El futuro que queremos"

Chile participó activamente en ambas conferencias mundiales y recogió los principios en el texto de la Ley $\mathrm{N}^{\circ} 19.300$, de 1994, en su triple dimensión, al consagrar el principio de participación, de acceso a la información ambiental, al mismo tiempo que establece recursos procesales destinados a facilitar el acceso a la justicia de las personas que participan en los procesos de evaluación ambiental, así como en materia de daño al medio ambiente, entre otros.

Por su parte la reforma a la institucionalidad ambiental, introducida por la Ley $\mathrm{N}^{\circ} 20.417$, busca fortalecer tales principios, en complemento con la Ley N $\mathrm{N}^{\circ}$ 20.600: Crea los tribunales ambientales.

Sin embargo, los avances conseguidos en el ámbito legislativo contrastan, a nivel nacional, con la implementación de la normativa en esta materia, la cual da cuenta de las deficiencias que aún persisten en los esfuerzos destinados a articular los objetivos del crecimiento económico, de la protección del medio ambiente y de los aspectos sociales del desarrollo.

El creciente nivel de conflictividad social y consecuente judicialización generada por los proyectos del sector eléctrico, confirma tal hipótesis, en circunstancias en que una de las causales de esta realidad es la defectuosa aplicación del principio de participación en la evaluación de impacto ambiental de los proyectos del sector.

En este orden de ideas el presente manuscrito describirá en primer lugar el Principio 10 de la "Declaración de Río", para luego analizar el contenido de las alegaciones de terceros a los proyectos eléctricos motivadas por defectos en la aplicación del principio de participación. Por último, se realizará un análisis sobre el aporte de la entrada en vigencia de los tribunales ambientales en materia de acceso a la justicia ambiental, especialmente desde la perspectiva de la protección del principio de participación.

${ }^{1}$ Organización de Naciones Unidas, El futuro que queremos, A/CONF.216/L.1, 19 de junio de 1992. 


\section{Principio 10 De la “Declaración de Río”}

\section{Antecedentes.}

El paradigma del desarrollo sustentable nace luego de la toma de conciencia, a nivel mundial, del carácter finito de los recursos naturales y como una manera de justificar el crecimiento económico, el cual, desde ahora, deberá realizarse integrando los objetivos del desarrollo económico, la protección del medio ambiente y los intereses sociales. De lo contrario, tal crecimiento se enfrenta a las limitaciones impuestas por la naturaleza y la sociedad.

Esta noción se asienta política y jurídicamente en la "Declaración de Río" de $1992^{2}$. Su realización depende de la aplicación de los principios contenidos en tal "Declaración", elaborada con ocasión de la Cumbre de Naciones Unidas sobre el Medio Ambiente y el Desarrollo, organizada en Brasil, en junio 1992. Entre dichos principios se encuentra el principio 10 sobre participación, acceso a la información y acceso a la justicia ambiental, definido en los siguientes términos: "El mejor modo de tratar las cuestiones ambientales es con la participación de todos los ciudadanos interesados, en el nivel que corresponda. En el plano nacional, toda persona deberá tener acceso adecuado a la información sobre el medio ambiente de que dispongan las autoridadespúblicas, incluida la información sobre los materiales y las actividades que encierran peligro en sus comunidades, así como la oportunidad de participar en los procesos de adopción de decisiones. Los Estados deberán facilitar y fomentar la sensibilización y la participación de la población poniendo la información a disposición de todos. Deberá proporcionarse acceso efectivo a los procedimientos judiciales y administrativos, entre éstos el resarcimiento de daños y los recursos pertinentes".

El documento final de la Cumbre de 2012, "El futuro que queremos", reafirma este principio y su vínculo con la realización del desarrollo sustentable al indicar: "Recalcamos que la participación amplia del público y el acceso a la información y los procedimientos judiciales y administrativos son esenciales para promover el desarrollo sostenible"3.

En esta misma ocasión Chile lideró un proceso de discusión relativo a la adopción de un instrumento regional destinado a mejorar el acceso a la información, a la participación ciudadana y al acceso a la justicia en la toma de decisiones del desarrollo sostenible. Ocho gobiernos latinoamericanos han adherido hasta ahora a la iniciativa: Chile, Costa Rica, República Dominicana, México, Panamá, Paraguay, Perú y Uruguay.

\footnotetext{
${ }^{2}$ Pieratti, Gértrude - Prat, Jean Luc, Droit, Économie, Écologie et développement durable: des relations nécessairement complémentaires, mais inévitablement ambigües, en Revue Juridique de l'Environnement, 1 (2000), p. 435.

${ }^{3}$ Organización de Naciones Unidas, cit. (n. 1), párr. 43.
} 
Es importante resaltar que en todos los documentos antes mencionados existe un tratamiento conjunto para los tres elementos que componen el principio 10, a saber: participación ciudadana, acceso a la información y acceso a la justicia ambiental. Esto se explica por el hecho que tales elementos constituyen partes de un engranaje en el que la realización de cada uno de ellos depende del otro y en el que el funcionamiento del conjunto, contribuye a la puesta en práctica de un concepto global, cual es el de la democracia ambiental ${ }^{4}$. En este orden de ideas es posible afirmar que la deficiente aplicación de cualquiera de los elementos del principio 10 afectará la efectividad de los demás. Así, las deficiencias en el acceso a la información, dificultará la realización de una participación eficaz en la toma de decisiones públicas y los obstáculos al acceso a la justicia, debilitará la protección de los derechos de participación y de acceso a la información.

A propósito del concepto de democracia ambiental, Brañes nos recuerda que el sistema democrático se construye sobre la base de una comunidad de personas regidas por un conjunto de reglas jurídicas, que cuenta con la participación directa o indirecta de un "alto número de personas" y en la que los llamados a decidir tienen alternativas reales y la posibilidad de optar. El cumplimiento de esta última condición exige a su vez que quienes decidan tengan garantizados sus derechos fundamentales, entre los cuales se encuentra el acceso a la justicia. Al mismo tiempo, señala que la aplicación del derecho ambiental es responsabilidad de los gobiernos, incluido el poder judicial, pero también de la ciudadanía, cuya participación debe estar asegurada por las autoridades a través de mecanismos de participación idóneos 5 .

La aplicación del principio 10 por parte de la autoridad se deberá realizar conforme a los estándares definidos en esta materia por la sociedad en su conjunto. Al respecto es posible constatar que los ciudadanos están cada vez mejor informados lo que les ha permitido tomar conciencia de los impactos ambientales producidos por el modo de consumo individual y de desarrollo del país. Paralelamente a este aumento de información y mayor conciencia, se ha incrementado el nivel de desconfianza respecto de las decisiones adoptadas por los poderes públicos que los representan, lo que se explica en razón de los desastres sanitarios y ambientales que, en muchas ocasiones, la autoridad, con conocimiento de causa, no ha podido de evitar. Este contexto ha hecho

${ }^{4}$ PrIEUR, Michel, La convention d'Aarhus, instrument universel de la démocratie environnementale, en Revue Juridique de l'Environnement, Num. spécial: La Convention de Aarhus (Paris, 1999), p. 9 ; SMITH, Graham, Deliberative democracy and the Environment (Londres, Routledge, 2007), 178 pp.

${ }^{5}$ BRAÑEs, Raúl, El acceso a la justicia ambiental en el distrito federal y la procuraduría ambiental y del ordenamiento territorial (México, Procuraduría Ambiental y del Ordenamiento Territorial del Distrito Federal, 2004), p. 27. 
evolucionar los modelos de adopción de decisiones de la administración la cual se ha orientado hacia la incorporación de los ciudadanos, en una óptica de democracia deliberativa ${ }^{6}$, en conformidad a lo dispuesto en el principio 10 de la "Declaración de Río": "En el plano nacional, toda persona deberá tener [...] la oportunidad de participar en los procesos de adopción de decisiones".

¿Pero qué debemos entender por cada uno de estos elementos del Principio 10 a la luz de la "Declaración de Río"?

\section{Concepto de acceso a la información ambiental}

El principio 10 de Río, en su óptica de acceso a la información, busca que cada individuo cuente a nivel global, nacional y local con la información ambiental que esté en manos de la autoridad incluida la que se refiere a actividades y sustancias peligrosas. Es justamente esta información la que permite a las personas interesadas, participar en la toma de decisiones: "Las deficiencias en la disponibilidad de información-incluidas las estadísticas ambientales-limitan, además de un eficaz accionar público, una participación efectiva de la sociedad civil en las decisiones"'.

El programa 21 elaborado también en la Conferencia de Naciones Unidas para el Medio Ambiente y el Desarrollo de 1992, aclara en esta materia que, en el contexto del desarrollo sostenible, cada persona es usuario y portador de información. Respecto del contenido de tal información, el texto aludido aclara que por información deben entenderse los datos, la información y el conjunto de experiencias y conocimientos.

Sin embargo, es necesario reconocer que el acceso a la información en materia ambiental va aparejado de una gran complejidad marcada por el desconocimiento general sobre el medio ambiente. En este sentido se ha destacado de manera particular la dificultad que tienen los países en desarrollo para reunir y evaluar datos y para transformarlos en información útil que pueda ser difundida y comprendida por la comunidad ${ }^{8}$. Una de las deficiencias que se observa en esta materia tanto a nivel regional y mundial es la existencia de una definición que permita contabilizar la riqueza para tener en cuenta el valor del medio ambiente?

En todo caso se debe admitir que la implementación del acceso a la

${ }^{6}$ LenzI, Cristian Luis, A politica democrática da sustantabilidade: os modelos deliberativo e associativo de democracia ambiental, en Ambiente \& Sociedade (Campinas, Sao Paulo, 2009), pp. 19-36.

${ }^{7}$ Comisión Económica para América Latina, La sostenibilidad del desarrollo a 20 años de la cumbre para la Tierra. Avances, brechas y lineamientos estratégicos para América Latina y el Caribe (Naciones Unidas, Santiago, Chile, 2012), p. 39

${ }^{8}$ Sección 4a: "Medios de Ejecución", capítulo $40^{\circ}$.

${ }^{9}$ Comisión Económica para América Latina, cit. (n. 9). 
información "favorece y hace efectivo el principio democrático", en ese contexto, el acceso a la información ambiental es una condición previa para aplicar los mecanismos de participación ciudadana y para alcanzar la justicia ambiental ${ }^{10}$.

\section{Concepto de participación ciudadana.}

El Programa 21 reafirma el principio 10 de la "Declaración de Río" al señalar que: "Uno de los requisitos fundamentales para alcanzar el desarrollo sostenible es la amplia participación de la opinión pública en la adopción de decisiones"11. En este contexto destaca la importancia de implementar la participación ciudadana en los procesos de evaluación de impacto ambiental. En el contexto latinoamericano se advierte que si bien es cierto que gran parte de los países de la región consagran en sus legislaciones el derecho de participación, los problemas se observan en la creación de instancias idóneas que permitan la implementación de mecanismos eficaces de participación, el caso chileno no escapa a esta realidad, tal como será analizado en el segundo acápite de este trabajo.

\section{Concepto de acceso a la justicia.}

Cappelletti sostiene que el acceso a la justicia "sirve para enfocar dos propósitos básicos del sistema jurídico por el cual la gente puede hacer valer sus derechos y/o resolver sus disputas, bajo los auspicios generales del Estado. Primero el sistema debe ser igualmente accesible para todos; segundo, debe dar resultados individual o socialmente justos" ${ }^{\prime 2}$.

En materia ambiental, el acceso a la justicia adquiere características particulares en razón de la naturaleza de los derechos que se pretenden proteger, pues en este caso se trata de derechos colectivos o difusos, enmarcados en los derechos de tercera generación, en oposición a los derechos puramente individuales ${ }^{13}$. En esta perspectiva Brañes definía el acceso a la justicia ambiental como "la posibilidad de obtener la solución expedita y completa por las autoridades judiciales de un conflicto jurídico de naturaleza ambiental,

${ }^{10}$ Bermúdez, Jorge, El acceso a la información pública y la justicia ambiental, en Revista de Derecho de la Pontificia Universidad Católica de Valparaiso, 34 ( $1^{\mathrm{er}}$ semestre de 2010), pp. 571-596.

${ }^{11}$ Organización de Naciones Unidas, Programa 21, Sección 3a: "Fortalecimiento del papel de los grupos principales”, capítulo $23^{\circ}$, párrafo 23,3 (1992).

${ }^{12}$ Capelletti, Mauro - Garth, Bryant, Acceso a la justicia. La tendencia en el movimiento mundial para hacer efectivos los derechos (México, Fondo de Cultura Económica, 1996), $154 \mathrm{pp}$.

${ }^{13}$ Tigroudja, Hélène, El derecho a un medio ambiente sano en la jurisprudencia de la Corte Europea de Derechos Humanos, en Revista de Derecho Ambiental, 3 (Santiago, Chile, 2009), pp. 155-167. 
lo que supone que todas las personas están en igualdad de condiciones para acceder a la justicia y para obtener resultados individual o socialmente justos (legitimidad activa)"14.

Además las causas ambientales poseen características muy propias que complejizan de manera especial el acceso a la justicia en este ámbito. Se trata, por ejemplo, del alto componente técnico científico de las causas ambientales y en consecuencia, de los altos costos económicos en la tramitación de las causas. Lo anterior genera una falta de igualdad para litigar entre las partes interesadas, pues la capacidad de recurrir a la justicia dependerá de la capacidad económica de cada una de ellas. Entre los costos económicos más gravosos para las partes se han identificado la remuneración de los abogados y de los expertos, los costos de traslado de los testigos para rendir prueba y los costos impuestos por el tribunal ${ }^{15}$. Al respecto la experiencia comparada ofrece distintas soluciones destinadas a disminuir la barrera económica para acceder a la justicia en materia ambiental.

En Estados Unidos, por ejemplo, se planteó el problema económico a propósito de la rendición de una prueba testimonial de un experto, que no se encontraba en el lugar de asiento del Tribunal, en circunstancias que la parte interesada en rendir esta prueba no contaba con recursos para financiar su traslado. Se trata del llamado "The Thelephone case", en el marco del cual los residentes de South Salem, Oregon, se oponen a la decisión de la autoridad ambiental que autoriza la utilización de un "spray" químico invasivo de especies. En este caso el juez propone, de manera muy innovadora para la época (años 80) y sin que esta situación estuviera prevista en el marco jurídico norteamericano, que el experto testificara por teléfono, para lo cual sostuvo que por el hecho de tratarse de un testimonio de tipo técnico, el cual se rendiría sobre la base de conocimientos científicos, no era necesario que la prueba testimonial se realizara ante el tribunal que estudiaba la causa ${ }^{16}$.

En España los tribunales tienen la posibilidad de solicitar informe de expertos a su costo, así por ejemplo la Corte podría contratar a un toxicólogo para ayudar a resolver materias técnicas. Sin embargo, el ejercicio de esta facultad no ha estado exenta de polémica, por el hecho de que sea el tribunal el que decida de manera discrecional, cuándo una parte litigante no está en

${ }^{14}$ Brañes, Raúl, El acceso a la justicia ambiental en América Latina (México D.F., Programa de Naciones Unidas para el Medio Ambiente, Oficina regional para América Latina y el Caribe, febrero de 2000).

${ }^{15}$ Comisión Económica para Europa, Convention d'Aarhus: guide d'application (ECE/CEP/72, 2000), p. 172.

${ }^{16}$ Sferrazza, Lynn, Financial and Other Barriers, en Stec, Stephen (editor), Handbook on Access to Justice under the Aarbus Convention (Szentendre, The Regional Environmental Center for Central and Eastern Europe, 2003), p. 55 y 213-214. 
condiciones de asumir el costo de este tipo de informes, en cuyo caso deberá realizarse con cargo a los fondos de la judicatura ${ }^{17}$.

En el marco de la legislación comparada, en particular la europea, se han dictado leyes en materia de asistencia legal gratuita, para lo cual se solicita que la demanda interpuesta tenga un mínimo de posibilidades de éxito ${ }^{18}$. Holanda va mucho más lejos en este sentido, al contar con asistencia legal gratuita especializada en litigación ambiental.

Además de los obstáculos al acceso a la justicia generados por cuestiones económicas, se advierte también la dificultad para que los grupos de personas interesadas se organicen y recurran ante la justicia conjuntamente, dada la naturaleza colectiva del derecho que se busca proteger.

La superación de los obstáculos al acceso a la justicia antes enunciados depende, según Brañes, de la existencia de un "marco jurídico que sea congruente con la naturaleza de los intereses que se deben tutelar judicialmente", el que a su juicio no existe, por lo menos en la forma que él considera, sería lo deseable. En este orden de ideas, él reconoce que ha sido justamente la ausencia de este marco jurídico, el que "ha determinado una situación de inaccesibilidad a la justicia ambiental y ha contribuido de una manera importante a la ineficacia del derecho ambiental, comprometiendo la protección del medio ambiente y la viabilidad del desarrollo sostenible"19.

Por su parte en el marco del "Convenio de Aarhus" ${ }^{20}$, considerado un modelo exitoso en esta materia, se han identificado los requisitos básicos para la puesta en práctica de este principio de acceso a la justicia en materia ambiental: i) Los órganos encargados del conocimiento de estos procedimientos deben ser independientes e imparciales; $i$ ) Las soluciones debe ser adecuadas y efectivas; iii) Los procedimientos deben ser justos, equitativos, abiertos y no prohibitivamente costosos; iv) La interpretación de la legitimación activa debe ser entendida de manera lo más ampliamente posible ${ }^{21}$.

Otra de las soluciones propuestas por la doctrina (Savoia, Pring) para

\footnotetext{
${ }^{17}$ Economic and Social Council, Workshop on Access to Justice in Environmental Matters under the Aarhus Convention (3 de octubre de 2001), p. 9.

${ }^{18}$ Legislación alemana: "Código de Procedimiento Administrativo", sección 166a; "Código de Procedimiento Civil”, 1661 N 2.

${ }^{19}$ Brañes, Raúl, El acceso a la justicia ambiental en América latina, cit. (n. 14).

${ }^{20} \mathrm{El}$ "Convenio sobre el acceso a la información, la participación del público en la toma de decisiones y el acceso a la justicia en materia de medio ambiente", fue firmado durante la IV Conferencia Ministerial sobre el Medio Ambiente en Europa, celebrada en Aarhus, Dinamarca. Aquél fue negociado en el marco de la Comisión Económica para Europa y entró en vigencia en 2001, luego de alcanzar las 16 ratificaciones.

${ }^{21}$ Comisión Económica para Europa, Un medio ambiente para Europa (ECE CEP24, 1995).
} 
superar los obstáculos al acceso a la justicia en materia ambiental, ha sido la creación de tribunales especializados ${ }^{22}$.

Pues bien, tal como se anunció en la introducción de este trabajo, las deficiencias observadas respecto de la implementación del principio de participación ciudadana en el proceso de evaluación de impacto ambiental de los proyectos eléctricos, han dado lugar a acciones judiciales en contra de las decisiones administrativas que han autorizado la ejecución de los mismos, poniendo de manifiesto que la debilidad de uno de los elemento del principio 10 , en este caso la participación ciudadana, activa otro de sus elementos, como es el del acceso a la justicia. Así y en consideración primero, al hecho que los elementos que componen este principio son interdependientes y segundo, a que los ciudadanos interesados ${ }^{23}$ han considerado vulnerado su derecho a participar en la tramitación ambiental de dichos proyectos, se ha abierto una compuerta a la judicialización de las decisiones adoptadas por la autoridad ambiental, tal como se expone a continuación.

\section{LA DEBILIDAD EN LA IMPLEMENTACIÓN DE LA PARTICIPACIÓN CIUDADANA COMO FUENTE DE LA JUDICIALIZACIÓN DEL SECTOR ELÉCTRICO}

1. Participación ciudadana en el contexto de la evaluación de impacto ambiental de proyectos eléctricos.

Si se tiene presente que el principio de participación persigue incorporar a los ciudadanos en la toma de decisiones para ponderar los distintos puntos de vista e intereses, éste puede considerarse como una herramienta de gran utilidad en la prevención de conflictos. A contrario sensu, es legítimo presumir, que deficiencias en su implementación pueden favorecer el enfrentamiento de posiciones. A este propósito Mirosevic señala que la participación permite reducir el nivel de judicialización, dado que "propicia su solución en una fase anterior" ${ }^{24}$. Para ello es necesario que se trate de una participación oportuna

${ }^{22}$ Savoia, Remo, Administrative, Judicial and Other Means of Access to Justice, en STEC, Stephen (editor), Handbook on Access to Justice under the Aarbus Convention (Szentendre, The Regional Environmental Center for Central and Eastern Europe, 2003), p. 40; PrIng, George - PrIng, Catherine, Greening Justice, Creating and Improving Environmental Courts and Tribunals (The Acces Initiative, 2009), $111 \mathrm{pp}$. Río”.

${ }^{23}$ El término "interesado" es la nomenclatura utilizada por la "Declaración de

${ }^{24}$ Mirosevic, Camilo, La participación ciudadana en el procedimiento de evaluación de impacto ambiental y las reformas introducidas por la Ley $N^{\circ} 20.417$, en Revista de Derecho de la Pontificia Universidad Católica de Valparaiso, 36 (Valparaíso, 2011, $1^{\text {er }}$ semestre), p. 286. 
y efectiva y no un procedimiento puramente formal que se transforme en fuente de frustraciones para la comunidad ${ }^{25}$.

El desarrollo eléctrico chileno de los últimos años confirma tal hipótesis. En efecto, un estudio efectuado por la Universidad de Chile para la Subsecretaría de Energía identifica entre las principales causas de la judicialización la insuficiente aplicación del principio de participación, originando como consecuencia la presentación de acciones en sede administrativa y judicial ${ }^{26}$.

El estudio al que se hace referencia se realizó sobre la base del análisis de trece proyectos del sector eléctrico, todos caracterizados por su alto nivel de conflictividad (Hidroaysén, Castilla, Campiche, Pacífico, Patache, Los Robles, Alto Maipo, El Tatio, San Pedro, Pirquenes, Achibueno, San Clemente, Eólico Chiloé) y por su representatividad en términos de fuentes (termoeléctrica, hidráulica, renovables), capacidad de generación (respecto de los proyectos de generación eléctrica) y ubicación geográfica (norte, centro y sur del país).

Cabe hacer presente que los casos analizados fueron tramitados bajo el imperio de la Ley $\mathrm{N}^{\circ} 19.300$ antes de la reforma introducida por la Ley $\mathrm{N}^{\circ}$ 20.417 , en conformidad a lo dispuesto por las normas transitorias de este último cuerpo legal, a excepción del "Proyecto Eólico Chiloé"27.

En este contexto, la normativa citada contemplaba en su artículo 29 inciso final un recurso de reclamación, conferido a las organizaciones ciudadanas con personalidad jurídica, por intermedio de sus representantes, y a las personas naturales directamente afectadas, que habiendo formulado observaciones al "Estudio de impacto ambiental" en tiempo y forma, consideren que éstas no hubieren sido debidamente ponderadas en los fundamentos de la resolución de calificación ambiental. Dicho recurso se presentaba ante la autoridad superior de la que la hubiere dictado, dentro de los quince días siguientes a su notificación, para que ésta, en un plazo de treinta días, se pronunciara sobre la solicitud. La presentación de este recurso no suspendía los efectos de la resolución recurrida.

Sin embargo, la Ley $\mathrm{N}^{\circ} 19.300$ no establecía una acción judicial destinada a impugnar la resolución administrativa que resolvía la reclamación de ter-

${ }^{25}$ Ibíd.

${ }^{26}$ Universidad de Chile, Análisis de casos de recursos administrativos y judiciales relacionados con la tramitación de permisos para proyectos del sector eléctrico y sus efectos en las inversiones del sector energía (Santiago, de Chile, Subsecretaría de Energía, 2012).

${ }^{27}$ Artículo 1 transitorio: "Los proyectos o actividades sometidos al Sistema de Evaluación de Impacto Ambiental previos a la publicación de la presente ley, se sujetarán en su tramitación y aprobación a las normas vigentes al momento de su ingreso". A este propósito ver también "Dictamen" de la Contraloría General de la República, $\mathrm{N}^{\circ} 1501$, de 11 de enero de 2011. 
ceros, fundada en la indebida ponderación de las observaciones, conforme al artículo 29 inciso final de este cuerpo legal. En este sentido, el tratamiento que otorgaba esta ley a la comunidad para ejercer su derecho a participar en el marco de la evaluación de impacto ambiental de los proyectos, era diferenciado en relación a los titulares de los mismos. De hecho, estos últimos gozaban de acción judicial para reclamar de la resolución administrativa que resolvía la reclamación presentada por el titular ante el Director Ejecutivo de la Comisión Nacional del Medio Ambiente, en contra de la resolución que negaba lugar a una "Declaración de impacto ambiental" o ante el Consejo Directivo de la Comisión Nacional del Medio Ambiente, en contra de la resolución que rechazaba o establecía exigencias a un "Estudio de impacto ambiental”, en los términos del artículo 20 de la Ley $\mathrm{N}^{\circ} 19.300$, anterior a la reforma y del artículo 42 del Reglamento del sistema de evaluación de impacto ambiental ${ }^{8}$.

\section{Reclamación por indebida ponderación de observaciones ciudadanas en} sede administrativa.

El estudio identifica setenta y una vías de intervención administrativa iniciadas en el marco de los proyectos analizados ${ }^{29}$, de las cuales cincuenta y dos tuvieron lugar en el contexto de la evaluación de impacto ambiental. Veintidós de estas últimas fueron iniciadas por terceros, los cuales fundaron sus reclamaciones en la indebida ponderación de las observaciones ciudadanas, en conformidad al artículo 29 inciso final de la Ley $\mathrm{N}^{\circ} 19.300$ y 45 del Reglamento del sistema de evaluación de impacto ambiental ${ }^{30}$.

En el estudio citado se señala que el análisis de las acciones de reclama-

${ }^{28}$ Artículo 42. "En contra de la resolución que niegue lugar a una Declaración de impacto ambiental, procederá la reclamación ante el Director Ejecutivo de la Comisión Nacional del Medio Ambiente. En contra de la resolución que rechace o establezca condiciones o exigencias a un Estudio de impacto ambiental, procederá la reclamación ante el Consejo Directivo de la Comisión Nacional del Medio Ambiente". Estos recursos deberán ser interpuestos por el titular del proyecto o actividad dentro del plazo de treinta días contado desde la notificación de la resolución impugnada.

${ }^{29} \mathrm{El}$ mismo estudio define la intervención administrativa como: "denominación de todas las formas de intervención ante la autoridad administrativa que da origen a un procedimiento administrativo particular", Universidad de Chile, cit. (n. 26), p. 28.

${ }^{30}$ Artículo 45.- "Las organizaciones ciudadanas y las personas naturales a que se refiere el artículo 28 de la Ley, cuyas observaciones no hubieren sido debidamente ponderadas en los fundamentos de la respectiva resolución, podrán presentar recurso de reclamación ante la autoridad superior de la que la hubiere dictado, dentro de los quince dias siguientes a su notificación. El recurso deberá indicar qué observaciones, de aquellas formuladas en la oportunidad legal, no fueron debidamente ponderadas, y los fundamentos de dicho reclamo. El recurso no suspenderá los efectos de la resolución recurrida". 
ción por indebida ponderación de observaciones ciudadanas no significó, en ningún caso, que la autoridad ambiental entrara a calificar si procedía jurídicamente dejar sin efecto o revocar la resolución de calificación ambiental. Por el contrario, la autoridad ambiental se limita a determinar si las observaciones fueron o no debidamente ponderadas, ordenando ponderar nuevamente las observaciones o complementar lo efectuado anteriormente cuando correspondiera ${ }^{31}$.

Las acciones identificadas en el estudio involucran a siete de los trece proyectos en análisis, lo cual deja en evidencia la envergadura de la problemática ${ }^{32}$.

${ }^{31}$ Universidad de Chile, cit. (n. 26), p. 49.

${ }^{32}$ Recursos de reclamación en contra de la Resolución exenta $\mathrm{N}^{\circ} 256 / 09$, de 30 de marzo de 2009, de la Comisión Regional del Medio Ambiente de la Región Metropolitana, que calificó favorablemente y aprobó con condiciones el "Proyecto Hidroeléctrico Alto Maipo”, interpuestos por: Enrique Cruzat T.; Junta de Vigilancia del Río Maipo, Coordinadora ciudadana No Alto Maipo, Armin Von Plate Harries y Udo Von Plate Harries; Asociación de Canalistas del Canal de Pirque, recursos de reclamación interpuestos en contra de la Resolución exenta $N^{\circ} 225$, de 13 de mayo de 2011, que calificó favorablemente el "Proyecto Hidroeléctrico Aysén", interpuestos por Enrique Alcalde U., Juan C. Cisternas, Francisco Velásquez M. Recursos de reclamación en contra de la Resolución exenta $\mathrm{N}^{\circ} 118$, de 23 de octubre de 2008, de la Comisión Regional del Medio Ambiente de la Región de Los Ríos, que calificó favorablemente el "Proyecto Central Hidroeléctrica San Pedro", interpuesto por Claudio Donoso H., Alejandro Lagos L., Orlando Romero L., Sociedad Pueblito Expediciones Ltda. Recursos de reclamación en contra de la Resolución de calificación ambiental $\mathrm{N}^{\circ} 43$, de 11 de mayo de 2011, que aprueba el "Proyecto Central Termoeléctrica Patache", dictada por el SEA de la I Región de Tarapacá, interpuestos por Junta de Vecinos Caleta Chanavaya, Arturo Neira V., Junta de Vecinos Caleta Chanavaya y Hugo Gutiérrez G. Recurso de reclamación en contra de la Resolución exenta $\mathrm{N}^{\circ} 226$ de la Comisión Regional del Medio Ambiente de la Región de Antofagasta, que autoriza la fase de exploración del "Proyecto Geotérmico de los Géisers del Tatio", interpuesto por la I. Municipalidad de San Pedro de Atacama. Recursos de reclamación en contra de la Resolución exenta $\mathrm{N}^{\circ}$ 229/2008, de 3 de julio de 2008, de la Comisión Regional del Medio Ambiente de Antofagasta, que califica favorablemente el "Proyecto Perforación Geotérmica Profunda El Tatio”, Fase I, interpuestos por Marisol López E., comunidad Indígena Quechua Sumac Llajta. Recursos de reclamación en contra de la Resolución exenta $\mathrm{N}^{\circ} 214$, de 4 de diciembre de 2008, de la Comisión Regional del Medio Ambiente de la VII Región del Maule, que aprueba el "Proyecto Central Termoeléctrica Los Robles", interpuestos por: Sindicato Número 2 de Pescadores Artesanales, Acuicultores y Recolectores de Orilla de Loanco, Federación de Sindicatos de Trabajadores, Buzos, Pescadores y Recolectores de Orilla Constitución, Sindicato de Trabajadores Independientes, Pescadores Artesanales, Buzos, Mariscadores, Algueros, Acuicultores y Actividades conexas de la Caleta de Loanco, S.T.I. Pescadores Artesanales, Buzos, Mariscadores y Algueros de Pellines, Federación de Sindicatos de Pescadores Artesanales de la Región del Maule, Guadalupe Muñoz R., Ilustre Municipalidad de Constitución, José Ignacio Pinochet 


\section{Cuestionamientos a la participación ciudadana en sede judicial}

La discusión de esta materia en sede judicial es más bien escasa. Sólo tres de los proyectos eléctricos, objeto del estudio en comento, abordaron la problemática de la participación ciudadana en sede judicial, vía acción de protección. Se trata del proyecto termoeléctrico Los Robles ${ }^{33}$, del proyecto hidroeléctrico Alto Maipo ${ }^{34}$ y del proyecto geotérmico El Tatio ${ }^{35}$, en el marco de los cuales los terceros (personas naturales directamente afectadas por los proyectos, figuras políticas como alcaldes y diputados y organizaciones ciudadanas con personalidad jurídica) dieron inicio a los procesos judiciales, fundados en la afectación a ciertas garantías consagradas en la Constitución Politica de la República, tales como: el derecho a vivir en un ambiente libre de contaminación (artículo $19 \mathrm{~N}^{\circ} 8 \mathrm{C}$.Pol.), el derecho a la igualdad (artículo 1 C.Pol.), el derecho a participar con igualdad de oportunidades en la vida nacional (artículo 1 inciso $5^{\circ} \mathrm{C}$.Pol.) y el derecho a la propiedad (artículo $19 \mathrm{~N}^{\circ} 24$ C.Pol.) ${ }^{36}$.

Dentro de los fundamentos utilizados por los terceros a los proyectos eléctricos analizados, que justifican la arbitrariedad o ilegalidad de la resolución de calificación ambiental contra la cual se dirigen tales acciones de protección, se encuentra la falta o indebida ponderación de las observaciones

O., Carlos Zúñiga D. Recursos de reclamación en contra de la Resolución de calificación ambiental $\mathrm{N}^{\circ} 44$, de 11 de mayo de 2011, mediante la cual se aprobó el "Proyecto Central Termoeléctrica Pacífico”, interpuestos por: Junta de Vecinos San Pedro de Caleta Chanavayita y Arturo Neira Valdivia.

${ }^{33}$ Corte de Apelaciones de Talca, rol $N^{\circ} 72 / 2009$ : acción de protección que impugna la Resolución exenta $\mathrm{N}^{\circ}$ 214/08 de la Comisión Regional del Medio Ambiente de la VII Región del Maule, de 4 de diciembre de 2008.

${ }^{34}$ Octava Sala de la Corte de Apelaciones de Santiago, rol N ${ }^{\circ} N^{\circ} 851-2010$ : acción de protección que impugna Resolución exenta $N^{\circ} 82 / 2010$ dictada por la Comisión Nacional del Medio Ambiente.

${ }^{35}$ Corte de Apelaciones de Antofagasta, rol № 402-2008, contra Resolución exenta $N^{\circ}$ 0229/200A, de 3 de julio de 2008, dictada por la Comisión Regional del Medio Ambiente Región de Antofagasta.

${ }^{36}$ Sin perjuicio de lo anterior, cabe reconocer también que el estudio aludido da cuenta de discusiones centradas sobre la necesidad de realizar un estudio de evaluación de impacto ambiental en lugar de una "Declaración de impacto ambiental", de manera a hacer efectivo el proceso de consulta indígena del "Convenio 169" de la Organización Internacional del Trabajo dentro del marco de participación ciudadana prevista por la antigua legislación en el caso de los "Estudios de impacto ambiental" Esta cuestión no será tratada en esta ocasión, por considerar que desde un punto de vista metodológico, que se trata de una temática compleja que excede el análisis de la participación ciudadana regulada por la Ley $\mathrm{N}^{\circ}$ 19.300. A este propósito véase: MoraGA, Pilar, La conflictividad el sector indigena. El caso de Convenio 169 de la OIT, en Anuario de Derecho Público (agosto 2012). 
ciudadanas, en los términos establecidos por la Ley $\mathrm{N}^{\circ} 19.300$, antes de la reforma introducida por la Ley $\mathrm{N}^{\circ} 20.417$.

Sin embargo, el único caso en que la cuestión de la participación se plantea como un argumento central del recurso de protección es en el marco del proyecto hidroeléctrico Alto Maipo, pues el recurrente solicita derechamente que "se acojan las observaciones al proyecto". Estas observaciones decían relación con tres temas principales: que el proyecto de generación de electricidad ( $545 \mathrm{MW}$ ) no contemplaba en su estudio la línea de transmisión; que la realización del proyecto involucraba la tala de olivillos y guayacanes, las cuales eran especies protegidas por la Ley de bosque nativo y por último, la ausencia de estudios en materia de cambio climático, en especial sobre el flujo y calentamiento del agua del caudal afectado ${ }^{37}$.

En este caso, la Corte resuelve cada uno de los puntos que fueron objeto de observación de parte del recurrente, pero no se pronuncia sobre la eventual falta de ponderación de las observaciones ciudadanas, a excepción de la discusión relativa a la temática del cambio climático. A este propósito, la Corte se limita a indicar en el considerando $\mathrm{N}^{\circ} 12$ del fallo, que las observaciones fueron "debidamente ponderadas".

En todo caso, es relevante destacar que dentro del marco del estudio en análisis, la utilización de la acción de protección no es excepcional y que muy por el contrario, ésta parece ser la vía de acción preferida de los terceros que se oponen a la ejecución de los proyectos eléctricos en sede judicial ${ }^{38}$.

Esta realidad se condice con la situación observada en América Latina en el marco de causas ambientales, lo que ha llevado a algunos autores (Brañes) a señalar que: "la justicia constitucional ha transformado al derecho ambiental en un "derecho vivo", en aquellos países donde las constituciones políticas han sufrido un proceso de "enverdecimiento" ${ }^{39}$. El concepto "enverdecimiento" al que se refiere el autor, dice relación con los textos constitucionales

\footnotetext{
${ }^{37}$ En este caso la Corte concluye que no existe acción u omisión arbitraria que haga procedente el recurso. Para ello desestima cada una de las alegaciones de fondo antes descritas. Respecto de la tala de especies protegidas por la Ley $\mathrm{N}^{\circ} 20.283$, la Corte precisa en el considerando $\mathrm{N}^{\circ} 11$ del fallo, que dicho cuerpo legal no prohíbe de manera absoluta la corta de especies nativas y que lo que necesita es un plan de manejo tal como se contempla en el "Estudio de impacto ambiental" del proyecto. En materia de cambio climático, la Corte señala que este tema se incluye en el "Estudio de impacto ambiental", el cual incorpora estudios de meteorología y climatología conforme a los términos del plan de acción de cambio climático (considerando $\mathrm{N}^{\circ} 12$ ).

${ }^{38}$ De las 46 vías de intervención identificadas en sede jurisdiccional, 33 correspondían a recursos de protección.

${ }^{39}$ BraÑES, Raúl, El acceso a la justicia ambiental en América latina, cit. (n. 14).
} 
latinoamericanos que consagraron el derecho a vivir en un medio ambiente sano, en sus diversas nomenclaturas ${ }^{40}$.

Así, Brañes reconoce la contribución de la acción de protección en materia de acceso a la justicia ambiental en el contexto latinoamericano y al mismo tiempo enfatiza en el hecho de que "las acciones constitucionales, deben considerarse como métodos de excepción en tanto remedios procesales de naturaleza eminentemente cautelar, que no pueden resolver todos los problemas que plantea dicho acceso"41. En esta óptica realiza un llamado a no considerar esta contribución del recurso de protección en materia ambiental como "un punto de arribo, sino como un punto de inicio", el que en el caso chileno estaría marcado por la entrada en vigencia de tribunales especializados en materia ambiental.

\section{TRIBUnALES AMBIENTALES:}

\section{¿NUEVO ESTÁNDAR DE PROTECCIÓN DEL DERECHO A PARTICIPAR?}

\section{Mejoramiento del estándar de participación en el marco de la evaluación de impacto ambiental.}

La entrada en vigencia de la Ley $\mathrm{N}^{\circ} 20.417$ significó un fortalecimiento de la participación ciudadana, en especial en el marco de la evaluación de impacto ambiental de los proyectos ${ }^{42}$. Lo anterior se explica por cuatro razones principales.

En primer lugar, se amplían las oportunidades de efectuar observaciones a los proyectos sometidos a evaluación ambiental, las cuales tienen lugar, desde la entrada en vigencia de este cuerpo legal, no sólo en el marco de los estudios de impacto ambiental (artículo 29 inciso $1^{\circ}$ de la Ley $\mathrm{N}^{\circ} 19.300$ ), sino también en aquellos casos en que el procedimiento de evaluación de tal estudio sea objeto de aclaraciones, rectificaciones o ampliaciones que afecten sustantivamente al proyecto (artículo 29 inciso $2^{\circ}$ de la Ley $\mathrm{N}^{\circ} 19.300$ ). Otra oportunidad, que incorpora la Ley $\mathrm{N}^{\circ} 20.417$ para que la comunidad participe formulando observaciones, es en el contexto de las "Declaraciones de impacto ambiental" referidas a proyectos que generen cargas ambientales para las comunidades próximas, cuando lo soliciten a lo menos dos organizaciones ciudadanas con personalidad jurídica, a través de sus representantes, o como mínimo diez personas naturales directamente afectadas (artículo 30 bis inciso $1^{\circ}$ de la Ley $\mathrm{N}^{\circ} 19.300$ ). Ahora si durante el procedimiento de evaluación de la "Declaración de impacto ambiental", ésta hubiese sido objeto

\footnotetext{
${ }^{40}$ Ibíd.

${ }^{41}$ Ibíd.

${ }^{42}$ Mirosevic, Camilo, cit. (n. 24).
} 
de aclaraciones, rectificaciones o ampliaciones que afecten sustantivamente los impactos ambientales del proyecto, también procede una nueva etapa de participación ciudadana, conforme a lo establecido por el artículo 30 bis inciso $2^{\circ}$ de la Ley $\mathrm{N}^{\circ} 19.300$.

Con la incorporación de estas nuevas instancias de participación aumenta el universo de proyectos susceptibles de ser objeto de observaciones de parte de la comunidad en el marco de la evaluación de impacto ambiental y con ello se amplía a un número mayor de personas la posibilidad de participar en estos procesos. Esta afirmación adquiere aún más relevancia si se considera que el 95\% de los proyectos ingresados a evaluación ambiental lo hacen por “Declaración” y sólo el 5\% por "Estudio", en conformidad a los artículos 10 y 11 de la Ley $\mathrm{N}^{\circ} 19.300$, respectivamente.

En segundo lugar, la reforma a la institucionalidad ambiental contenida en la Ley $\mathrm{N}^{\circ} 20.417$ introduce un cambio sustancial en la forma de apreciar las observaciones, pasando del término "ponderación" a "consideración", el cual no es fútil. En adelante, las observaciones formuladas por los ciudadanos son parte del proceso de calificación y en ese contexto, la autoridad ambiental (el Servicio de Evaluación Ambiental) debe hacerse cargo de éstas, pronunciándose fundadamente respecto de todas ellas en su resolución (artículo 29 inciso $3^{\circ}$ y artículo 30 bis inciso $4^{\circ}$ de la Ley $N^{\circ} 19.300$ ). En esta misma óptica, se establece la obligación de publicar Dicho pronunciamiento en la página web del servicio con a lo menos cinco días de anticipación a la calificación del proyecto en conformidad al artículo 29 inciso $3^{\circ}$ y 30 bis inciso $4^{\circ}$ de la Ley $\mathrm{N}^{\circ} 19.300$.

En tercer lugar, la Ley 20.417 modifica el recurso de reclamación del antiguo artículo 29 inciso final de la $\mathrm{N}^{\circ}$ Ley 19.300, al vincular este recurso (artículo 29 inciso final y 30 bis inciso $5^{\circ}$ de la Ley $\mathrm{N}^{\circ} 19.300$ ) con el artículo 20. Con ello se equiparan los plazos del recurso de reclamación del titular (artículo 20 de la Ley $\mathrm{N}^{\circ} 19.300$ ) y el recurso de reclamación que puede interponer la comunidad, los cuales quedan homologados en 30 días.

Por último, dicha reforma legal crea además un nuevo recurso de reclamación que la comunidad puede presentar ante el tribunal ambiental en contra de la resolución administrativa que resuelve la reclamación por indebida consideración de las observaciones ciudadanas, contenido en el artículo 29 inciso final y el artículo 30 bis inciso $5^{\circ}$ de la Ley $\mathrm{N}^{\circ}$ 19.300. De esta manera las acciones destinadas a dar protección al principio de participación no se agotan en sede administrativa, tal como estaba previsto por la antigua legislación, creando así un nuevo rol a la justicia especializada en la protección del derecho a participar. 
2. Nuevo rol de la justicia en la protección del derecho a participar en la evaluación de impacto ambiental.

La Ley $\mathrm{N}^{\circ}$ 20.600: Crea los tribunales ambientales establece, entre las competencias del nuevo órgano jurisdiccional, el conocimiento de las reclamaciones presentadas por terceros a los proyectos sometidos a evaluación ambiental que estimen que sus observaciones no fueron consideradas en conformidad a los artículos 29 y 30 bis y en relación con el artículo 20 de la Ley N 19.300: "Los Tribunales Ambientales serán competentes para: 6) Conocer de las reclamaciones que interponga cualquierpersona natural o jurídica en contra de la determinación del Comitéde Ministros o Director Ejecutivo que resuelva el recurso administrativo cuando sus observaciones no hubieren sido consideradas en el procedimiento de evaluación ambiental, en conformidad con lo dispuesto en los artículos 29 y 30 bis de la Ley $N^{\circ} 19.300$, en relación con el artículo 20 de la misma ley" (artículo 17 de la Ley $N^{\circ} 20.600$ ).

Será competente para conocer de tal reclamación el tribunal ambiental del lugar en que haya sido evaluado el proyecto por la correspondiente Comisión de Evaluación o el Director Ejecutivo del Servicio de Evaluación Ambiental, en su caso (artículo 17 inciso $6^{\circ}$ ) de la Ley $\mathrm{N}^{\circ} 20.600$ )

Respecto a la procedencia del recurso de reclamación antes mencionado, un grupo de ministros del Tribunal Constitucional realizó una prevención en el sentido de aclarar que este recurso tendría lugar cada vez que las observaciones ciudadanas no hubieren sido "debidamente" consideradas en la respectiva "resolución de calificación ambiental". A su entender, esto significa que las causales que habilitan a las personas naturales y/o jurídicas para recurrir ante un tribunal ambiental se configuran: $i$ ) cuando se omite considerar sus observaciones; y $i$ ) cuando éstas se rechazan sin fundamento bastante ${ }^{43}$.

Así las cosas, sería posible concluir, al menos desde un punto de vista teórico, que el reforzamiento del principio de participación ciudadana en el procedimiento de evaluación de impacto ambiental de los proyectos, estaría acompañado de un reforzamiento del acceso a la justicia ambiental, destinado a proteger tal principio, con lo cual sería esperable una estabilización de los conflictos ambientales, en sectores de gran sensibilidad social, como lo es el sector eléctrico. Cabe recordar en este sentido que la historia de la Ley $\mathrm{N}^{\circ}$ 20.600 da cuenta que uno de los objetivos de la reforma a la institucionalidad ambiental, introducida por la Ley $\mathrm{N}^{\circ} 20.417$, era el de dar mayor eficacia a la protección ambiental, a través, entre otros, de un mejor acceso a la justicia

\footnotetext{
${ }^{43}$ La sentencia continúa con la siguiente expresión: "Uno de los sinónimos del verbo "considerar" es precisamente "juzgar", es decir, sopesar el mérito de la observación y resolver en consecuencia". Ministros del Tribunal Constitucional señores Vodanovic, Navarro, Viera-Gallo y Aróstica, sentencia rol N²180-2012, fojas 198, p. 53.
} 
ambiental. En esta misma óptica, se afirmó que uno de los objetivos que perseguía el proyecto de ley que crea los Tribunales Ambientales era el de garantizar el acceso a la justicia ambiental y una tutela judicial efectiva, en los términos previstos en el número 8 del artículo 19 C.Pol. ${ }^{44}$.

Sin embargo, es necesario tener presente que si bien la reforma a la institucionalidad ambiental mejora el estándar de protección de la participación ciudadana en el contexto de la evaluación de impacto ambiental, en relación a la prevista por la antigua legislación, el real mejoramiento dependerá de la manera cómo se implemente la nueva normativa.

A su vez, tal hipótesis requiere ser complementada con ciertos matices que dicen relación con las temáticas de la legitimación activa de esta nueva acción de reclamación por indebida consideración de las observaciones ciudadanas en los procesos de evaluación ambiental de los proyectos, de competencia del Tribunal Ambiental, y la introducción, de manera inédita, en nuestra legislación de la figura del amicus curiae.

\section{Legitimidad activa.}

En general es posible señalar que la legitimidad activa en materia ambiental presenta ciertas complejidades particulares originadas, entre otros, por la necesidad de que la afectación al medio ambiente se transforme en una afectación a las personas, en conformidad con la teoría antropocéntrica que funda nuestro marco normativo ambiental. En este contexto, es necesario que exista interés para que exista acción.

Otra de las problemáticas ligadas con la cuestión de definir la legitimidad activa en materia ambiental se gesta por la naturaleza del derecho que se pretende proteger, de carácter colectivo y difuso, propio de los derechos humanos de tercera generación. Esto quiere decir que no se trata de un derecho individual, de carácter exclusivo, perteneciente a una persona, sino de un derecho que pertenece a un grupo de personas respecto del cual cada uno goza de parte de ese derecho. A su vez el carácter difuso se advierte por el hecho de que las personas interesadas son muchas veces indeterminadas e indeterminables y en consecuencia no poseen un interés individual, inmediato y exclusivo sobre el ambiente.

El concepto de la legitimación activa evolucionó durante la tramitación del proyecto que crea los Tribunales Ambientales, pues el texto definitivo resultó ser más restrictivo que la propuesta original.

La historia de la de ley que creó los tribunales ambientales deja constancia de la intención primera del proyecto, cual era la de consagrar un concepto amplio de legitimidad activa para todas las acciones susceptibles

\footnotetext{
${ }^{44}$ Biblioteca del Congreso Nacional, Historia de la Ley 20.600, pp. 7 y 66.
} 
de ser presentadas ante la nueva justicia especializada, en los términos del artículo 21 de la Ley $\mathrm{N}^{\circ} 19.880$, según el cual se consideran interesados en el procedimiento administrativo a: "1. Quienes lo promuevan como titulares de derechos o intereses individuales o colectivos./2. Los que, sin haber iniciado el procedimiento, tengan derechos que puedan resultar afectados por la decisión que en el mismo se adopte./3. Aquéllos cuyos intereses, individuales o colectivos, puedan resultar afectados por la resolución y se apersonen en el procedimiento en tanto no hay a recaido resolución definitiva".

El texto definitivo sin embargo, establece distintos tipos de legitimados activos, cuya definición se relaciona con cada una de las competencias definidas en el artículo 17 de la Ley $\mathrm{N}^{\circ} 20.600^{45}$.

En la cuestión que nos ocupa relativa a la acción de reclamación que se puede interponer ante el Tribunal Ambiental, en contra de la resolución administrativa que resuelve la reclamación por indebida consideración de las observaciones, la legitimación activa se define en los términos siguientes: “[...] podrán intervenir como partes en los asuntos de competencia de los Tribunales Ambientales [...]", "5)[...] Las personas naturales o juridicas que presentaron sus reclamaciones de conformidad a la ley" (artículo 18 de la $\mathrm{N}^{\circ}$ Ley 20.600).

${ }^{45}$ Artículo 18: "De las partes. Los organismos de la Administración del Estado y las personas naturales o jurídicas que se señalan, podrán intervenir como partes en los asuntos de competencia de los Tribunales Ambientales, que en cada caso se indican, conforme con la enumeración del articulo 17: 1) En el caso del número 1) cualquier persona que considere que los decretos que tal numeral menciona no se ajustan a la ley $N^{\circ} 19.300$ y le causan perjuicio. 2) En el caso del número 2), las personas naturales o jurídicas que hayan sufrido el daño o perjuicio; las municipalidades, por los hechos acaecidos en sus respectivas comunas, y el Estado, por intermedio del Consejo de Defensa del Estado. Deducida demanda por alguno de los titulares señalados no podrán interponerla los restantes, lo que no obsta a su derecho a intervenir como terceros coadyuvantes. En el caso del inciso quinto del artículo 43 de la Ley Orgánica de la Superintendencia Biblioteca del Congreso Nacional de Chile - www.leychile.cl-documento generado el 28-Sep-2012 del Medio Ambiente, la acción deberá siempre ejercerla el Consejo de Defensa del Estado como parte principal. 3) En el caso del número 3), las personas naturales o jurídicas directamente afectadas por la resolución de la Superintendencia del Medio Ambiente. 4) En el caso del número 4), la Superintendencia del Medio Ambiente. 5) En los casos de los números 5) y 6), las personas naturales y jurídicas que presentaron sus reclamaciones de conformidad a la ley. 6) En el caso del número 7), cualquier persona que considere que los actos administrativos que dicten los Ministerios o servicios públicos para la ejecución o implementación de las normas de calidad, emisión y planes de prevención o descontaminación, infrinjan la ley, las normas $y$ los objetivos de los instrumentos señalados. 7) En el caso del número 8), quien hubiese solicitado la invalidación administrativa o el directamente afectado por la resolución que resuelva el procedimiento administrativo de invalidación. En los procedimientos que se regulan en esta ley será aplicable lo dispuesto en el artículo 23 del Código de Procedimiento Civil. 8) Se presumirá que las municipalidades y el Estado tienen el interés actual en los resultados del juicio que dicha norma exige". 
De esta manera la legitimación activa se homologa a la definición de personas habilitadas a efectuar observaciones en el proceso de evaluación de impacto ambiental definida por la Ley $\mathrm{N}^{\circ} 19.300$.

\section{Integración de los amigos del Tribunal: El amicus curiae.}

La figura del amicus curiae o amigo del tribunal nace en el Derecho romano. En la era actual, esta institución se incorpora primero en el Derecho inglés, para luego propagarse al Derecho norteamericano y al de otros países de habla inglesa ${ }^{46}$. En el ámbito internacional, destaca su participación en los litigios que ventilan materias de derechos fundamentales ante tribunales internacionales (Corte Interamericana de Derechos Humanos, Tribunal Europeo de Derechos Humanos, Tribunal para la ex Yugoslavia) ${ }^{47}$, como en causas relacionadas con el comercio internacional, conocidas por el órgano de solución de diferendos de la Organización Mundial del Comercio ${ }^{48}$.

Fernández define el amicus curiae como "una herramienta procesal que permite a terceros que no son partes de una disputa judicial de trascendencia o interés público, presentarse en ella a los efectos de dar una opinión fundada sobre el tema debatido" ${ }^{49}$. De tal definición se desprenden los principales elementos que caracterizan esta institución: se trata de terceros ajenos al litigio, en cuya calidad están habilitados a emitir una opinión experta sobre el tema debatido en juicio y en el marco de causas en las que se ventilan temas de interés público.

Respecto de la definición de terceros que pueden participar como amigos del tribunal, la Ley $N^{\circ}$ 20.600: Crea los tribunales ambientales los indivi-

${ }^{46}$ Rule 18 de la Suprema Corte de Canadá, orden IV, \& I de las reglas de la Suprema Corte de India, rule 81 de la High Court de Nueva Zelanda y en "Australia Lange v. $A B C "(S 108 / 116)$.

${ }^{47}$ BAZÁn, Víctor, "Amicus Curiae" y la utilidad de su intervención procesal: Una visión de derecho comparado, con especial énfasis en el derecho argentino, en Revista del Centro de Estudios Constitucionales (Universidad de Talca, Chile, 2003), pp. 675 a 714.

${ }^{48} \mathrm{La}$ cuestión fue discutida a propósito de las siguientes controversias: Estados Unidos, establecimiento de derechos compensatorios sobre determinados productos de acero al carbono aleado de plomo bismuto y laminado caliente originarios de Reino Unido EUU causa plomo bismuto, WT/DS138/AB/R, 7 de junio de 2000; Estados Unidos, prohibición de las importaciones de determinados camarones y productos de camarón, WT/DS58/AB/R, 6 de noviembre de 1998; Comunidades Europeas, medidas que afectan al amianto y a los productos que contienen amianto, WT/ds135/ $\mathrm{AB} / \mathrm{R}, 12$ de marzo de 2001; Comunidades europeas-denominación comercial de sardinas, WT/DS231/AB/R, 26 de septiembre de 2002.

${ }^{49}$ Fernández, Mariano, Acceso a la justicia, democratización del proceso judicial, y propuestas para una regulación general del "amicus curiae" (Centro de Implementación de Políticas Públicas para la Equidad y el Crecimiento, Políticas Públicas Recomendación $\mathrm{N}^{\circ} 17$, 2005). 
dualiza como: "cualquier persona, natural o jurídica, que no sea parte en el proceso, que posea reconocida idoneidad técnica y profesional" (artículo 19). La implementación de esta "herramienta procesal", según nomenclatura utilizada por Fernández, ha demostrado, sobre todo en la práctica jurisprudencial norteamericana, que las opiniones expertas pueden ser presentadas por particulares (personas individuales, grupos de individuos, organizaciones no-gubernamentales, etc.), pero también por órganos del Estado ${ }^{50}$.

En cuanto al segundo elemento referido a la calidad de experto, la reciente legislación chilena exige que el tercero posea idoneidad técnica y profesional en las materias a las que se está refiriendo en su opinión, pero además que ésta sea reconocida. Dicho requisito ha generado interrogantes sobre la posibilidad de que los tribunales ambientales sometan el informe emanado de un "amigo del tribunal" a un estudio previo de admisibilidad, con el objeto de corroborar el cumplimiento de tal exigencia. Al respecto, las Comisiones Unidas y el poder ejecutivo aclaran esta cuestión durante la tramitación parlamentaria del proyecto de ley, al rechazar por unanimidad esta interpretación: "Si bien al momento de presentarse el informe deberá acreditarse la idoneidad técnica de quien lo emite, esta circunstancia no constituye requisito de admisibilidad"s1.

El tercer elemento de la definición de amicus curiae antes expuesta, dice relación con la necesidad de que las causas en las que participe un amigo del tribunal involucren un interés público relevante que, por su naturaleza, exceda el ámbito del interés de las partes y trate por ende, cuestiones de interés colectivo ${ }^{52}$. Esta característica explica la importante presencia de esta institución en causas que involucran el respeto a los derechos fundamentales o en los casos denominados por Dworkin "difíciles" (aborto, eutanasia) $)^{53}$. La Ley $\mathrm{N}^{\circ} 20.600$ recoge este elemento al exigir al tercero que desee presentar una opinión que contenga comentarios, observaciones o sugerencias respecto de la cuestión debatida ante el tribunal ambiental, que invoque el interés público (artículo 19).

Así las cosas, es posible constatar que el desarrollo de esta institución jurídica ha tenido lugar en el ámbito de derechos fundamentales y en causas de especial sensibilidad social y ética. En este orden de ideas cabe preguntarse por las motivaciones que llevan al poder legislativo a consagrarla, de manera inédita en el ordenamiento jurídico chileno, en el ámbito de la justicia especializada en materia ambiental. La historia de la Ley $\mathrm{N}^{\circ} 20.600$ informa

\footnotetext{
${ }^{50}$ BAzÁn, Víctor, cit. (n. 47), p. 257.

${ }^{51}$ Biblioteca del Congreso Nacional, Historia de la Ley 20.600, p. 537.

${ }^{52}$ BAZÁn, Víctor, cit. (n. 47), p. 258.

${ }^{53}$ Ibíd., p. 258.
} 
en este sentido, que las motivaciones que justificaron el establecimiento del amicus curiae son principalmente dos.

En primer lugar, destaca la posibilidad de que los tribunales ambientales cuenten con informes científicos versados que aporten conocimientos relevantes y objetivos en el juicio ${ }^{54}$. Tales informes permitirían mejorar el nivel del debate generado en torno al objeto del litigio, por el hecho de proporcionar al juez de la causa, argumentos que trascienden a los intereses de las partes del juicio.

En segundo lugar, la discusión parlamentaria subrayó el hecho de que la participación de amigos del tribunal en el ámbito de la justicia ambiental, permitiría fortalecer la participación ciudadana y la democracia ${ }^{55}$. Coincidiendo con tal visión, la Acordada $N^{\circ}$ 28/2004 de la Corte Suprema Argentina sostiene que: "la participación de amigos del Tribunal en causas de relevancia, en las cuales se ventilen cuestiones de interés público, favorece la participación ciudadana en la administración de justicia" ${ }^{56}$. Por su parte, Bazán, identifica los beneficios de la participación de amigos del tribunal en materia de democratización y transparencia de los debates judiciales, pues a su parecer el hecho de favorecer la participación de diversos actores en el debate de la controversia sometida a juicio, permite acercar al público a la discusión de fondo, la que en la mayoría de los casos le es ajena. El autor va aún más lejos al vincular la participación de los amigos del tribunal en juicio con la mayor legitimidad de los fallos emitidos por el poder judicial respecto de la comunidad. A su parecer, el hecho de admitir la participación de diversas ideas durante la tramitación de la controversia sometida al Juez de la causa, en litigios de especial sensibilidad social por el interés público que involucran, permite mejorar la razonabilidad de los fallos y con ello dar mayor legitimidad a la resolución que adopta el tribunal ${ }^{57}$. Ahora, para lograr tales objetivos, el académico destaca la necesidad que tal opinión sea tomada en cuenta por el Juez.

Esto último fue una cuestión debatida durante la tramitación de la Ley $\mathrm{N}^{\circ}$ 20.600: Crea los tribunales ambientales en el Congreso. En este sentido el profesor Tavolari señaló que era necesario que a objeto de dar sentido y seriedad a la presentación de las opiniones de los amicus curiae ante el tribunal ambiental, éste debía tener a la vista dicho informe en su sentencia. Ahora bien, esto no significa, a su juicio, que la falta de consideración del informe sea causa de impugnación de la sentencia ${ }^{58}$.

\footnotetext{
54 “Opinión” de Raúl Tavolari, en Historia de la Ley N²0.600, p. 531.

${ }^{55}$ Biblioteca del Congreso Nacional, Historia de la Ley 20.600, pp. 531 a 534.

${ }^{56}$ Corte Suprema de la Nación Argentina, Acordada $N^{\circ}$ 28/2004,.

${ }^{57}$ BAZÁN, Víctor, cit. (n. 47), p. 258.

${ }^{58}$ Biblioteca del Congreso Nacional, Historia de la Ley $N^{\circ} 20.600$, p. 531.
} 
La Ley $N^{\circ} 20.600$ establece finalmente, que tales informes deben ser "considerados" en sentencia definitiva: "la entrega de la opinión escrita no suspenderá, ni alterará la tramitación del procedimiento, pero el tribunal deberá considerarla en sentencia definitiva" (artículo 19, inciso $4^{\circ}$ de la Ley $\mathrm{N}^{\circ}$ 20.600). Respecto del contenido de la expresión "consideración", el mismo prof. Tavolari aclaró durante la discusión del proyecto de Ley que: "la legislación chilena en el artículo 170 del Código de Procedimiento Civil exige al tribunal que sus sentencias indiquen las consideraciones de hecho y de derecho en que se fundan y que la expresión "considerar" debia entenderse en el sentido de: la reflexión, meditación o cavilación que hace el tribunal respecto de los medios de prueba que se han acompañado, a diferencia de la prueba que debe ser "ponderada"s?.

Dos aspectos formales de la participación del amicus curiae en las causas que sean de conocimiento de los tribunales ambientales, merecen especial atención. Se trata en primer lugar, de la contabilización del plazo legal para la presentación de los informes, el cual es de 30 días corridos desde la publicación en el sitio electrónico del tribunal de la resolución que admite a tramitación la reclamación o la demanda por daño ambiental. El segundo aspecto se refiere a los requisitos de forma que exige la Ley $\mathrm{N}^{\circ} 20.600 \mathrm{al}$ informe que entregue el amicus curiae al tribunal ambiental, entre los cuales se contemplan: la entrega de un informe escrito, con tantas copias como partes litigantes hubiere, el cual debe ser patrocinado por un abogado (artículo 19). Ambos aspectos fueron objeto de debate durante la tramitación parlamentaria de la Ley $\mathrm{N}^{\circ} 20.600$, a propósito de los obstáculos al acceso a la justicia en materia ambiental. Respecto de la notificación en el sitio electrónico del tribunal, se hace presente que sólo un 32\% de la población en Chile cuenta con acceso a internet en el país, con lo cual se excluye a gran parte de la población de la posibilidad de notificarse de la resolución con la cual se da inicio a la contabilización del plazo legal para presentar informes técnicos, emanados de un amigo del tribunal. En lo relativo al patrocinio del abogado que requiere la presentación del informe del amicus curiae ante los nuevos tribunales ambientales, se ha señalado que en la práctica la participación de un abogado en la entrega de estos informes puede significar un obstáculo al acceso a la justicia en materia ambiental, al aumentar los costos de presentación de tal informe en razón de los honorarios del profesional aludido.

Por otra parte, la ley no aclara el procedimiento de entrega de los informes, ni el número de informes susceptibles de ser recibidos por el tribunal ambiental. Al respecto el Tribunal pleno de la Corte Suprema ha estimado que este hecho constituye una "falta de precisión en cuanto al procedimiento

${ }^{59}$ Ibíd., p. 536. 
de rendición de estos informes, considerando conveniente, en cambio, que sea el tribunal el que los requiera si la complejidad del caso sometido a su conocimiento lo justifica y se determine a lo menos un numero claro de informes que se pueda aceptar"60.

En todo caso, dicha opinión escrita que entregue un amigo del tribunal al tribunal ambiental, no suspenderá ni alterará la tramitación del procedimiento, ni tampoco le conferirá, a quien la emita, la calidad de parte.

En este contexto, es posible afirmar que pese a los defectos identificados anteriormente y que podrían significar un obstáculo a la participación de los amigos del tribunal ante el tribunal ambiental, la consagración de esta institución jurídica como un nuevo actor en la resolución de conflictos ambientales, puede ser beneficioso a más de un título en terrenos de conflicto caracterizados por una gran sensibilidad social y de alta complejidad técnica, como lo es el del desarrollo de los proyectos eléctricos.

\section{CONCLUSión}

La realización del desarrollo sustentable depende de la aplicación efectiva de los principios establecidos en la "Declaración de Río" de 1992, los cuales fueron reafirmados en el documento final de la Conferencia de Naciones Unidas sobre el Desarrollo Sustentable que tuvo lugar en Río de Janeiro Brasil veinte años más tarde, en 2012.

En el caso del principio 10 de tal "Declaración", es posible advertir que en la realidad se trata de tres principios (participación ciudadana, acceso a la información y acceso a la justicia ambiental) a los cuales se les otorgó un tratamiento conjunto en razón de su íntima vinculación, pues la aplicación de cada uno de ellos depende de la eficacia del otro.

A su vez, el primero de los elementos de este principio, la participación ciudadana, destaca como una importante herramienta en la prevención de conflictos socio-ambientales, en la medida que existan mecanismos de participación idóneos a través de los cuales la comunidad encuentra espacios deliberativos reales que la integren en los procesos de adopción de decisiones.

La judicialización de los proyectos eléctricos en nuestro país es un buen ejemplo de lo expuesto anteriormente, pues demuestra que el incumplimiento en las expectativas de una implementación eficaz del derecho a participar, en el marco de la evaluación de impacto ambiental de los proyectos, activa el mecanismo de protección del principio de participación a través de las acciones procesales previstas por la legislación, que en el caso chileno, sólo contemplaba el recurso de reclamación en sede administrativa, hasta antes

${ }^{60}$ Oficio $\mathrm{N}^{\circ} \mathrm{CL} / 99 / 2010$, de 30 de agosto de 2010. 
de la introducción de la reforma a la institucionalidad ambiental contenida en la Ley $\mathrm{N}^{\circ} 20.417$.

En este contexto de conflictividad del sector eléctrico, el fortalecimiento del principio de participación y de acceso a la justicia para su protección, introducido por la Ley $\mathrm{N}^{\circ} 20.417$, significa una oportunidad de encausar el debate relativo a la ejecución de proyectos eléctricos con alto impacto ambiental y social y por ende, una oportunidad de morigerar la tensión existente entre el interés de la comunidad de proteger su bienestar y el del medio ambiente y los intereses del crecimiento económico. En efecto, este cuerpo legal amplía el universo de proyectos susceptibles de ser objeto de observaciones ciudadanas en los procesos de evaluación de impacto ambiental, al mismo tiempo que exige a la autoridad que se haga cargo de todas y cada una de tales observaciones. En materia de acceso a la justicia la nueva normativa crea una acción de reclamación de la resolución que resuelve la reclamación presentada por la comunidad en sede administrativa, motivada en la indebida consideración de las observaciones, cuya conocimiento es competencia de los Tribunales Ambientales. A su vez, la introducción de la figura del amicus curiae puede significar una oportunidad al desarrollo de debates más transparentes, fundados en información objetiva e imparcial, capaz de brindar una mayor legitimidad a los procesos de adopción de decisiones en la esfera judicial y consecuentemente a los fallos emitidos por los tribunales ambientales, en litigios de especial sensibilidad social, como lo son los relativos al sector eléctrico.

Sin embargo, para que el fortalecimiento del derecho a participar pueda traducirse en un aporte concreto a la prevención de conflictos, es necesario que exista un convencimiento real de querer una sociedad fundada en un desarrollo sustentable que propicie una democracia deliberativa, que incluya en las decisiones los intereses de todos los actores de la sociedad. De lo contrario la frustración de la sociedad se traducirá en obstáculos para el crecimiento económico, para la protección del medio ambiente y el bienestar social.

\section{BIBLIOGRAFÍA}

BAzÁn, Víctor, “Amicus Curiae” y la utilidad de su intervención procesal: Una visión de derecho comparado, con especial énfasis en el derecho argentino, en Revista del Centro de Estudios Constitucionales (Universidad de Talca, Chile, 2003).

BermúDEZ, Jorge, El acceso a la información pública y la justicia ambiental, en Revista de Derecho de la Pontificia Universidad Católica de Valparaiso, 34 ( $1^{\mathrm{er}}$ semestre de 2010).

Biblioteca del Congreso Nacional, Historia de la Ley 20.600.

BraÑEs, Raúl, El acceso a la justicia ambiental en América Latina (México D.F., Programa 
de Naciones Unidas para el Medio Ambiente, Oficina regional para América Latina y el Caribe, febrero de 2000).

BRAÑEs, Raúl, El acceso a la justicia ambiental en el distrito federal y la procuraduría ambiental y del ordenamiento territorial (México, Procuraduría Ambiental y del Ordenamiento Territorial del Distrito Federal, 2004).

Capelletti, Mauro - Garth, Bryant, Acceso a la justicia. La tendencia en el movimiento mundial para hacer efectivos los derechos (México, Fondo de Cultura Económica, 1996).

Comisión Económica para América Latina, La sostenibilidad del desarrollo a 20 años de la cumbre para la Tierra. Avances, brechas y lineamientos estratégicos para América Latina y el Caribe (Naciones Unidas, Santiago, Chile, 2012).

Comisión Económica para Europa, Convention d'Aarhus: guide d'application (ECE/ $\mathrm{CEP} / 72,2000)$.

Comisión Económica para Europa, Un medio ambiente para Europa (ECE CEP-24, 1995).

Economic and Social Council, Workshop on Access to Justice in Environmental Matters under the Aarbus Convention (3 de octubre de 2001).

Fernández, Mariano, Acceso a la justicia, democratización del proceso judicial, y propuestas para una regulación general del "amicus curiae" (Centro de Implementación de Políticas Públicas para la Equidad y el Crecimiento, Políticas Públicas Recomendación $\left.\mathrm{N}^{\circ} 17,2005\right)$.

Lenzi, Cristian Luis, A política democrática da sustantabilidade: os modelos deliberativo $e$ associativo de democracia ambiental, en Ambiente \& Sociedade (Campinas, Sao Paulo, 2009).

Mirosevic, Camilo, La participación ciudadana en el procedimiento de evaluación de impacto ambiental y las reformas introducidas por la Ley $N^{\circ} 20.417$, en Revista de Derecho de la Pontificia Universidad Católica de Valparaíso, 36 (Valparaíso, 2011, $1^{\mathrm{er}}$ semestre).

Moraga, Pilar, La conflictividad el sector indígena. El caso de Convenio 169 de la OIT, en Anuario de Derecho Público (agosto 2012).

Organización de Naciones Unidas, El futuro que queremos, A/CONF.216/L.1, 19 de junio de 1992.

Organización de Naciones Unidas, Programa 21, Sección 3a: "Fortalecimiento del papel de los grupos principales".

Pieratti, Gértrude - Prat, Jean Luc, Droit, Économie, Écologie et développement durable: des relations nécessairement complémentaires, mais inévitablement ambigües, en Revue Juridique de l'Environnement, 1 (2000).

PRIEUR, Michel, La convention d' Aarhus, instrument universel de la démocratie environnementale, en Revue Juridique de l'Environnement, Num. spécial: La Convention de Aarbus (Paris, 1999).

PRING, George - PrIng, Catherine, Greening Justice, Creating and Improving Environmental Courts and Tribunals (The Acces Initiative, 2009).

Savoia, Remo, Administrative, Judicial and Other Means of Access to Justice, en STEC, Stephen (editor), Handbook on Access to Justice under the Aarbus Convention (Szentendre, The Regional Environmental Center for Central and Eastern Europe, 2003). 
Sferrazza, Lynn, Financial and Other Barriers, en Stec, Stephen (editor), Handbook on Access to Justice under the Aarhus Convention (Szentendre, The Regional Environmental Center for Central and Eastern Europe, 2003).

Smith, Graham, Deliberative democracy and the Environment (Londres, Routledge, 2007).

Tigroudja, Hélène, El derecho a un medio ambiente sano en la jurisprudencia de la Corte Europea de Derechos Humanos, en Revista de Derecho Ambiental, 3 (Santiago, Chile, 2009).

Universidad de Chile, Análisis de casos de recursos administrativos y judiciales relacionados con la tramitación de permisos para proyectos del sector eléctrico y sus efectos en las inversiones del sector energía (Santiago, de Chile, Subsecretaría de Energía, 2012). 
